treatment initiation is beneficial for the outcome of ACPA-negative RA as well, other diagnostics are required for the early identification of ACPA-negative RA. Disclosure of Interest: None declared

DOI: 10.1136/annrheumdis-2017-eular.3994

\section{FRI0132 HIGH DISEASE ACTIVITY IS A PREDICTOR OF DEPRESSION AND PERSISTENT DEPRESSION IN EARLY RHEUMATOID ARTHRITIS: RESULTS FROM THE ONTARIO BEST PRACTICES RESEARCH INITIATIVE (OBRI)}

R. Joshi ${ }^{1}$, M. Movahedi ${ }^{2,3}$, E. Rampakakis ${ }^{2}$, A. Cesta ${ }^{3}$, X. Li $^{3}$, S. Couto ${ }^{3}$, J. Sampalis ${ }^{2}$, C. Bombardier ${ }^{3,4,5}$, B. Kuriya ${ }^{6}$ on behalf of OBRI investigators. ${ }^{1}$ Department of Rheumatology, Brampton Civic Hospital, William Osler Health System, Brampton; ${ }^{2}$ JSS Medical Research, Montreal; ${ }^{3}$ Ontario Best Practices Research Initiative, Toronto General Hospital, University Health Network; ${ }^{4}$ Division of Rheumatology, Mount Sinai Hospital; ${ }^{5}$ Department of Medicine (DOM) and Institute of Health Policy, Management, and Evaluation (IHPME);

${ }^{6}$ Sinai Health System, University of Toronto, Toronto, Canada

Background: The prevalence of depression among individuals with rheumatoid arthritis (RA) may be as high as $40 \%$ but persistence of depression over time is relatively unknown. Uncontrolled inflammation may drive severe disease and, in turn, inflammation and high disease activity are hypothesized to mediate depressive symptoms.

Objectives: The aims of this analysis were to: (1) describe the prevalence of depression at baseline and determine how often depression persists over time; (2) determine whether there is an association between changes in disease activity and depression over time among individuals with early RA (ERA).

Methods: ERA patients enrolled in the Ontario Best Practices Research Initiative (OBRI) with ERA ( $\leq 1$ year disease duration) and $\geq 2$ years of follow-up were included. Persistent depression was defined as self-reported depression at baseline and at $>50 \%$ of visits over the first 2 years. The association between baseline disease activity, measured by the Clinical Disease Activity Index (CDAl), and depression at baseline or persistent depression was evaluated with multivariate logistic regression. The General Estimation Equation was also used to explore the association between changes in CDAI disease activity over time and risk of depression.

Results: 469 patients with ERA $(72.9 \%$ female) were included with a mean (SD) age of 56.8 (13.6) years. Mean (SD) disease parameters were: CDAl: 22.9 (14.1); DAS28: 4.6 (1.5); and HAQ disability Index: 1.1 (0.75). At baseline, the prevalence of depression was $26 \%$, and $23 \%$ reported persistent depression. Persistent depression was significantly higher in patients with moderate CDAI $(19 \%)$ and high CDAl $(29 \%)$ compared to those in CDAl low disease activity (LDA) or remission $(16 \%, \mathrm{p}=0.02)$. After adjusting for potential confounders (sex, rheumatoid factor status, prior use of csDMARDs, current use of bDMARDs, HAQ disability index, number of comorbidities), increased CDAI at baseline was significantly associated with both baseline depression and persistent depression (OR: $1.04 ; 95 \% \mathrm{Cl}: 1.01-1.06, \mathrm{p}=0.002$ ). Female gender (OR: $3.17 ; 95 \% \mathrm{Cl}$ : $1.50-6.68 p=0.002$ ) and greater number of comorbidities at baseline (OR: 1.68; $95 \%$ Cl: $1.47-1.93, p<0.001)$ were also associated with persistent depression. Over the course of follow-up, the risk of depression was significantly higher among patients with moderate disease activity compared to those in CDAI LDA or remission (OR: 1.16; $95 \% \mathrm{Cl}: 1.04-1.29, \mathrm{p}=0.006$ ). The risk of depression was substantially greater for those with high disease activity (OR: 1.32; $95 \% \mathrm{Cl}$ : 1.15-1.52) over time compared to those achieving LDA or remission states.

Conclusions: Depression in ERA is common and initial high disease activity increases the risk of depression as well as its persistence. High CDAl during the early years of follow-up was also an independent predictor of depression. This highlights the importance of intervening during the "window of opportunity" to control disease activity and the potential to mitigate adverse health outcomes, including depression.

Disclosure of Interest: R. Joshi Grant/research support from: OBRI was funded by peer reviewed grants from CIHR (Canadian Institute for Health Research), Ontario Ministry of Health and Long-Term Care (MOHLTC), Canadian Arthritis Network (CAN) and unrestricted grants from: Abbvie, Amgen, Celgene, Hospira, Janssen, Lilly, Novartis, Merck, Pfizer, Roche, Sanofi, \& UCB, M. Movahedi Employee of: OBRI/JSS Medical Research, E. Rampakakis Employee of: JSS Medical Research, A. Cesta Employee of: OBRI, X. Li Employee of: OBRI, S. Couto Employee of: OBRI, J. Sampalis Employee of: Head of JSS Medical Research, C. Bombardier Grant/research support from: OBRI was funded by peer reviewed grants from CIHR (Canadian Institute for Health Research), Ontario Ministry of Health and Long-Term Care (MOHLTC), Canadian Arthritis Network (CAN) and unrestricted grants from: Abbvie, Amgen, Celgene, Hospira, Janssen, Lilly, Novartis, Merck, Pfizer, Roche, Sanofi, \& UCB, B. Kuriya Grant/research support from: OBRI was funded by peer reviewed grants from CIHR (Canadian Institute for Health Research), Ontario Ministry of Health and Long-Term Care (MOHLTC), Canadian Arthritis Network (CAN) and unrestricted grants from: Abbvie, Amgen, Celgene, Hospira, Janssen, Lilly, Novartis, Merck, Pfizer, Roche, Sanofi, \& UCB

DOI: 10.1136/annrheumdis-2017-eular.2311

\section{FRI0133 IS THERE INCREMENTAL MENTAL HEALTH BURDEN ASSOCIATED WITH RHEUMATOID ARTHRITIS?}

V. Strand ${ }^{1}$, M. Kosinski ${ }^{2}$, R. Rendas-Baum ${ }^{2}$, D. Brooks ${ }^{3}$, R. Ganguly ${ }^{3}$.

${ }^{1}$ Stanford University, Palo Alto, CA; ${ }^{2}$ Optum, Inc., Eden Prairie, MN:

${ }^{3}$ GlaxoSmithKline, Collegeville, $P$, United States

Background: Rheumatoid arthritis (RA) patients are more likely to experience depression. ${ }^{1}$ This comorbidity is associated with increased disability, use of healthcare services, and mortality risk. ${ }^{2,3}$ The association between RA and other mental health disorders has received limited attention and there remains a need to further demonstrate and understand the impact of RA on mental health.

Objectives: Evaluate the mental health burden of RA patients based on the analysis of Short Form-36v2 Health Survey (SF-36v2) mental health (MH) and role emotional (RE) domain scores from two independent general population databases in the US and Europe.

Methods: The mental health burden associated with RA was analyzed by comparing mean SF-36v2 MH and RE scores of individuals self-reporting RA (with or without depression) and the scores from 2 benchmark samples (individuals without RA, individuals with depression and no RA) in two large cross-sectional survey studies (QualityMetric's 2009 General US Population Norming Study of the SF-36v2 and the 2014 European National Health and Wellness Survey). Multivariate regression methods were used to adjust each benchmark sample to the distribution of the RA sample in terms of age and gender. Differences between samples were interpreted with respect to minimally important differences: 3 points for $\mathrm{MH} ; 4$ points for RE.

Results: The US (2009) and European (2014) samples included 4,042 and 81,366 individuals, respectively. Compared with individuals without RA or depression, mean $\mathrm{RE}$ scores were significantly $(P<0.001)$ lower for RA patients without depression in the US (-7.75 points) and Europe (-5.31 points). Likewise, mean MH scores were significantly $(P<0.001)$ lower among RA patients without depression in the US (-4.85 points) and Europe ( -5.03 points) compared with individuals without RA or depression. Compared to individuals with depression and no RA, mean RE and $\mathrm{MH}$ scores were 5 to 10 points higher $(P<0.001)$ for RA patients without depression in both the US and Europe. Comparisons of RE and MH scores between RA patients with and without comorbid depression showed that comorbid depression was associated with 2 to 6 points lower scores $(P<0.01)$ in $\mathrm{RE}$ and $\mathrm{MH}$ domains, in both the US and Europe.

Conclusions: RA is associated with significant and clinically meaningful mental health burden as measured by SF-36v2 MH and RE domains. Results comparing scores between RA patients with and without comorbid depression suggest that there is an incremental mental health burden associated with RA, often exceeding minimally important differences among US patients.

References:

[1] Dickens C, et al. Psychosomatics. 2003:44(3):209-215.

[2] Ang DC, et al. J Rheumatol. 2005;32(6):1013-1019.

[3] Kessler RC, et al. J Occupat Environ Med. 2003;45(12):1257-1266.

Disclosure of Interest: V. Strand Consultant for: Abbvie, Amgen, AstraZeneca, Biogenldec, Boehringer Ingelheim, Celltrion, Crescendo, Genentech/Roche, GSK, Janssen, Lilly, Merck, Novartis, Pfizer, Regeneron, Samsung, Sanofi and UCB, M. Kosinski Employee of: Optum, R. Rendas-Baum Employee of: Optum, D. Brooks Shareholder of: GlaxoSmithKline, Employee of: GlaxoSmithKline, R. Ganguly Shareholder of: GlaxoSmithKline, Employee of: GlaxoSmithKline

DOI: 10.1136/annrheumdis-2017-eular.3575

\section{FRI0134 CLUSTER ANALYSIS OF PULMONARY LESIONS IN RHEUMATOID ARTHRITIS (RA); AIRWAY DISEASE IS SHARED AND CRITICAL PULMONARY ABNORMALITY IN RA}

A. Tanaka, Y. Namiki, R. Yamazaki, H. Okada, S. Arai, T. Owada, R. Maezawa, M. Arima, K. Kurasawa. Departoment of Rheumatology, Dokkyo Medical University, Shimotuga-Gun, Japan

Background: Rheumatoid arthritis (RA) is a systemic inflammatory disease that affects joints and various organs including the lung. The pulmonary involvement is critical for prognosis of the patients and decision of the treatment. Moreover, the pulmonary involvement showed various abnormalities such as interstitial pneumonia (ILD) and airway disease (AD). Importantly, a pulmonary abnormality coexists with other ones in RA patients. There have been large numbers of studies on the prevalence of pulmonary abnormalities and clinical features of patients with these lesions. However, it remains to be elucidated what existence pattern of pulmonary abnormalities RA patients have.

Objectives: To reveal the existence pattern of the pulmonary abnormalities in RA patients using cluster analysis, and to clarify the clinical features of patients with multiple pulmonary abnormalities.

Methods: Subjects were consecutive 208 RA patients who were treated with bDMARDs as the first one from Feb. 2004 to Sep. 2015 in our department and received HRCT scan before and after the therapy. Pulmonary abnormalities were classified into 4 categories (ILD, nodular lesions, AD and other) and 20 lesions such as ground-glass opacity, reticular pattern, bronchiolitis and bronchiectasis and were examined their existence and distribution. Cluster analysis was conducted according to the existence of the lesions by Ward method. Clinical features were analyzed through reviewing medical records.

Results: Subjects were 208 RA cases (M/F; 64/144, mean age 59.2 year-old, 